\title{
Recovery of Valuable Metals from Acoustic Magnet Swarf Slurry
}

\author{
Wei-Sheng Chen ${ }^{1}$, Li-Pang Wang ${ }^{2, *}$, and Chen-Yao Hung 1,* \\ ${ }^{1}$ Department of Resources Engineering, National Cheng Kung University, No.1, University Road, Tainan City, Taiwan \\ ${ }^{2}$ Graduate Institute of Environmental Engineering and Management, National Taipei University of Technology, Taipei, Taiwan
}

\begin{abstract}
Acoustic magnet swarf slurry (AMSS) has 1900 tons production worldwide. The composition of AMSS contained $12.45 \%$ neodymium, $34.35 \%$ iron, $0.48 \%$ boron and $52.5 \%$ of cooling reagent. Removing cooling reagent and decreasing iron dissolution percent were achieved by oxidation roasting and selective leaching. Selective leaching removed $89 \%$ of iron with parameter of $0.5 \mathrm{M} \mathrm{HCl}$, solid-liquid ratio equal to $1: 100,4$ hours at $95^{\circ} \mathrm{C}$. The rest of iron was separated by solvent extraction with Aliquat 336 as extractant.

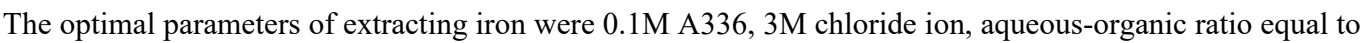
1:3 and mixed for 1 minute. Oxalic acid added to solution after solvent extraction to precipitate neodymium. The final product was neodymium oxidize with $99 \%$ of purity by calcined neodymium oxalate at $900^{\circ} \mathrm{C}$ for 0.5 hour. The recovery percent of neodymium was $99 \%$.
\end{abstract}

\section{Introduction}

The production of acoustic magnet swarf slurry (AMSS) depended on the production of acoustic magnet. There are 1900 tons of AMSS production per year worldwide [1-3]. AMSS was produced in molding processing of acoustic magnet [4]. The demand of acoustic magnet will increase at percent of $20 \%$ for past 10 years [5-6]. Due to the high demand of acoustic magnet and in view of economy and limited material, the recovery of valuable metals in AMSS is necessary. There are few literatures studied on AMSS; however, many kinds of method studied on recovering metals from permanent magnet. Compared to many kinds of methods [7-10], hydrometallurgy was a better one from energy perspective.

According to different acid we had been studied [1113], $\mathrm{HCl}$ has a great effect on leaching iron. During iron removing process, $20-30 \%$ of metals present in the leachate will lose due to co-precipitation [14]. Oxidation roasting is carried out to decrease iron leaching efficiency. In separation, solvent extraction is chosen because of highly selective on different elements. In recent years, different extractants had been studied [15-18]. Phosphorous-based extractants play a key role in rare earth [19]. However, phosphorous-based extractants was not a great choice on AMSS due to the co-extraction effect on iron and rare earth elements. Aliquat 336 (A336) is chosen because of high loading capacity of iron (III) in chloride-contained solution [20]. In purification process, oxalate acid has high selective precipitation on rare earth. Hence, we will build a recovery process with the reagent above to achieve effective result. In this study, we focused on finding optimal experimental parameters and built a recycle process for AMSS.

\section{Materials and Methods}

\subsection{Raw material analysis and pretreatment}

AMSS dried by furnace and obtained moisture content equal to 50\%. Crystal phase and condition of AMSS were analysed by X-ray diffraction (XRD, Dandong, DX-2700) and Thermogravimetric Analysis (TGA, Perkin Elmer, Pyris Diamond TG/DTA). After the oxidation roasting process, all the AMSS after oxidation roasting was sieved through a $38 \mathrm{~mm}$ mesh (\#400 mesh) to liberate elements cladded in oxidized iron. The composition of AMSS dissolved by aqua regia and the composition of solution in this experiment were determined by Inductively Coupled Plasma Optical Emission Spectrometry (ICPOES, Varian, Vista-MPX).

\subsection{Selective leaching}

Main purpose of selective leaching is to dissolve the valuable metals and precipitated most iron into residue. The equilibrium time and temperature were fixed to 4 hours and $368 \mathrm{~K}$. Other parameters were experimented like acidity $(0.2-0.8 \mathrm{~N})$, solid-liquid ratio $(20-200 \mathrm{ml} / \mathrm{g})$ were set for finding the optimal condition to leach valuable metals.

\subsection{Solvent extraction}

Aliquat 336 (A336) as an extarctant is able to separate iron from solution. Extraction of Iron into A336 was an effective reaction within 30 seconds, so we fixed mixing time as 1 minute. Concentration of chloride ion (0.1-3.0

\footnotetext{
* Corresponding author: kuniwang@ntut.edu.tw_N46051114@ncku.edu.tw
} 
N) and extarctant $(0.2-2.0 \mathrm{~mol} / \mathrm{L})$ were adjusted by deionized water and kerosene. Aqueous-organic ratio (1$10 \mathrm{ml} / \mathrm{ml}$ ) was also experimented to find out the optimal parameters.

\subsection{Chemical precipitation and calcination}

Oxalic acid was first dissolved by deionized water and adjusted into $1 \mathrm{~mol} / \mathrm{L}$ solution. Different volume (1-20 ml) of oxalic acid added to stripping solution. Precipitate would turn into oxidation by $1073 \mathrm{~K}$ calcination. The purity of final product was determined by XRD.

\section{Results and discussion}

\subsection{Raw material analysis and pretreatment}

The composition of AMSS were shown in Table 1. The main character of AMSS was the cooling reagent which accounts for $52.5 \%$. It was important to remove cooling reagent before leaching to avoid separating AMSS from acid. Therefore, oxidation roasting not only decreased iron leaching percent but also removed cooling reagent.

Table 1. Composition of AMSS

\begin{tabular}{ccccc}
\hline Element & $\mathrm{Nd}$ & $\mathrm{Fe}$ & $\mathrm{B}$ & $\begin{array}{c}\text { Cooling } \\
\text { reagent }\end{array}$ \\
\hline $\mathrm{wt} \%$ & $12.45 \%$ & $34.35 \%$ & $0.48 \%$ & $52.5 \%$ \\
\hline
\end{tabular}

Diffraction patterns (Fig. 1) showes the specific alloy $\left(\mathrm{Nd}_{2} \mathrm{Fe}_{14} \mathrm{~B}\right)$ peak. It also revealed the AMSS containing oxidation like $\mathrm{Nd}_{2} \mathrm{O}_{3}$ and $\mathrm{Fe}_{3} \mathrm{O}_{4}$. It was estimated that the friction between machine and raw magnet casting caused oxidation of AMSS.

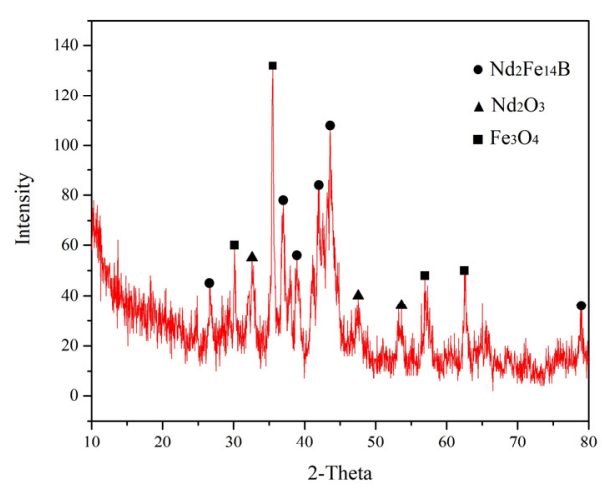

Fig. 1. The XRD pattern of raw material.

The result of TG-DTA diagram is presented in Fig. 2. Three reverse points at $550,850,1000{ }^{\circ} \mathrm{C}$ revealed the different crystal phase generation including $\mathrm{Fe}_{2} \mathrm{O}_{3}, \mathrm{Fe}_{3} \mathrm{O}_{4}$, $\mathrm{Nd}_{2} \mathrm{O}_{3}$ and $\mathrm{NdBO}_{3}$.

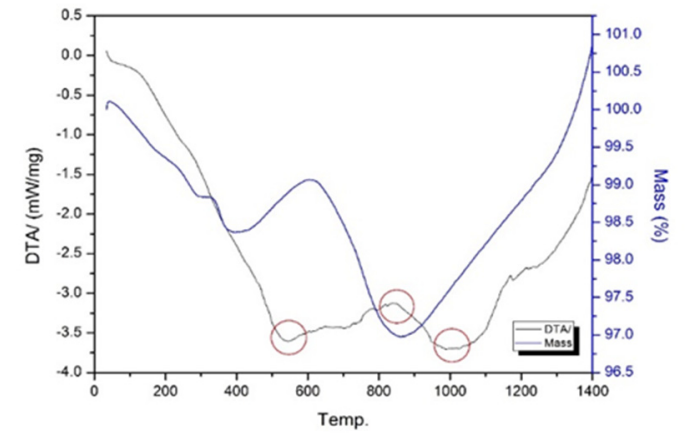

Fig. 2. Thermal property of AMSS by TG-DTA

The main crystal phase and their leaching percent with same condition which AMSS was roasted on different temperature is presented in Table 2. FD in Table 2 indicated that AMSS was fully dissolved by aqua regia. In the Table 2 the increase of roasting temperature caused the increase of oxidized percent and the decrease the weight percent on each metals. Moreover, since the $\mathrm{Fe}_{2} \mathrm{O}_{3}$ phase participated in the reaction, the leaching percent of neodymium and iron decreased. In this process, leaching of neodymium and reducing iron dissolved percent were the main objective. Hence, we chose $600^{\circ} \mathrm{C}$ as the optimal roasting temperature.

Table 2. Crystal phase and leaching efficiency of different roasting temperature with fixed condition

\begin{tabular}{|c|c|c|c|c|}
\hline & $\operatorname{ppm}(\%)$ & $\mathrm{Nd}$ & $\mathrm{Fe}$ & $\mathrm{B}$ \\
\hline \multirow[t]{3}{*}{$600^{\circ} \mathrm{C}$} & \multicolumn{4}{|c|}{ Crystal phase: $\mathrm{NdBO}_{3}, \mathrm{Fe}_{3} \mathrm{O}_{4}$} \\
\hline & FD & 2292 & 5208 & 70.84 \\
\hline & $\mathrm{HCl}$ & $97 \%$ & $10.4 \%$ & $98 \%$ \\
\hline \multirow[t]{3}{*}{$850^{\circ} \mathrm{C}$} & \multicolumn{4}{|c|}{ Crystal phase: $\mathrm{Fe}_{3} \mathrm{O}_{4}, \mathrm{Fe}_{2} \mathrm{O}_{3}, \mathrm{Nd}_{2} \mathrm{O}_{3}$} \\
\hline & FD & 2179 & 4944 & 66.65 \\
\hline & $\mathrm{HCl}$ & $73 \%$ & $1.25 \%$ & $99 \%$ \\
\hline \multirow[t]{3}{*}{$1050^{\circ} \mathrm{C}$} & \multicolumn{4}{|c|}{ Crystal phase: $\mathrm{Fe}_{2} \mathrm{O}_{3}, \mathrm{Nd}_{2} \mathrm{O}_{3}$} \\
\hline & FD & 1922 & 4512 & 66.98 \\
\hline & $\mathrm{HCl}$ & $58 \%$ & $0.52 \%$ & $99 \%$ \\
\hline
\end{tabular}

\subsection{Selective leaching}

Fig. 3 illustrates the effect of acid concentration in selective leaching process by increasing the acidity from $0.2 \mathrm{~N}$ to $0.8 \mathrm{~N}$ and obtained $99 \%$ of neodymium dissolved on $0.5 \mathrm{~N} \mathrm{HCl}$. Since neodymium achieved equilibrium, more $\mathrm{H}^{+}$ion reacted with iron caused leaching of iron increasing continually. 


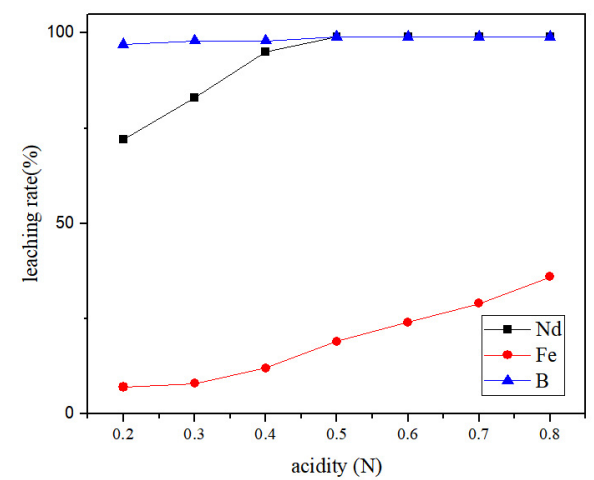

(1:100, 368K, 5 hours)

Fig. 3. Efficiency of acidity on leaching of AMSS

The efficiency of solid-liquid ratio is illustrated on Fig. 4. Neodymium dissolved from $50 \%$ to $99 \%$ with solidliquid ratio from $1: 20$ to $1: 100$. However, leaching efficiency of iron under this condition increased to $25 \%$ which also needed to concern. Based on the literature, VanderHoogerstraete mentioned that the key point of removing iron in leaching process was acidity and time [21]. Hence, the lower acidity could precipitate iron and higher solid-liquid ratio could dissolve iron cladded on the surface. Therefore, we chose $0.4 \mathrm{~N} \mathrm{HCl}$ and solid-liquid ratio of 0.01 as optimal parameter.

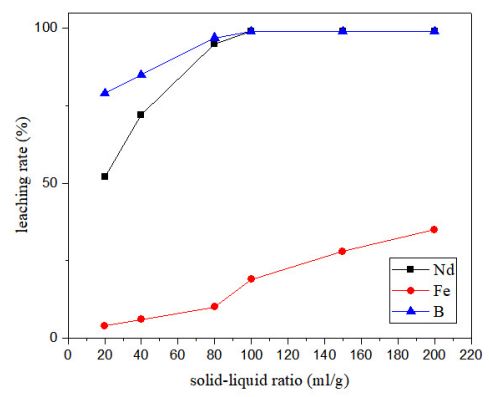

(0.5M, 368K, 5 hours)

Fig. 4. The effect of solid-liquid ratio on leaching process

\subsection{Solvent extraction}

The extraction reaction of A336 with metal is presented as Eq. 1 [23]:

$$
\begin{gathered}
\mathrm{Fe}_{\mathrm{Aq}}^{3+}+4 \mathrm{Cl}_{\mathrm{Aq}}^{-}+\mathrm{R}_{3} \mathrm{NCH}_{3} \mathrm{Cl}_{\text {org }} \\
\leftrightarrow \mathrm{R}_{3} \mathrm{NCH}_{3} \cdot \mathrm{FeCl}_{4 \mathrm{org}}+\mathrm{Cl}^{-}
\end{gathered}
$$

Fig. 5 illustrates that $2 \mathrm{~N}$ chloride ion could extract $99 \%$ of iron. However, when chloride concentration more than $3 \mathrm{~N}$, the extraction reaction could be improved by increasing $\left[\mathrm{FeCl}_{4}^{-}\right]$to make whole reaction stabilized [16].

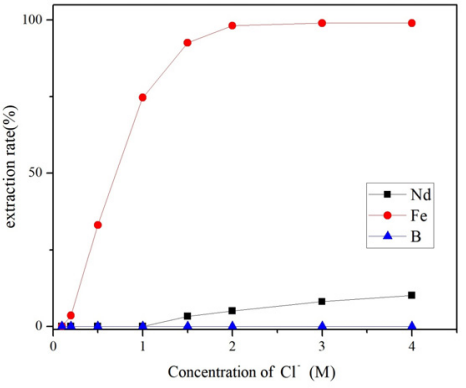

(A/O ratio=1:1, 0.1M A336, 1minute)

Fig. 5. The efficiency of $\mathrm{HCl}$ concentration on extraction

In Fig. 6, the result shows that extraction percent of neodymium increased from 1.0 to $1.5 \mathrm{~N}$ but achieve equilibrium on $2.0 \mathrm{~N}$ A336. Because of the low distribution ratio of neodymium in A336, the extraction percent was less than $10 \%$ even with higher concentration of A336. Higher concentration of A336 increased extraction percent of iron and achieved equilibrium in 1.0 $\mathrm{N}$.

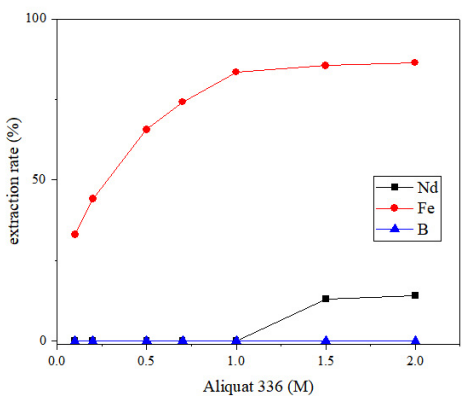

$(\mathrm{A} / \mathrm{O}$ ratio $=1: 1,1 \mathrm{M} \mathrm{HCl}, 1$ minute $)$

Fig. 6. The efficiency of A336 concentration

Extraction percent of iron decreased from $99 \%$ to $68.8 \%$ with aqua-organic from $1: 1$ to $1: 10$. As neodymium purity concern, we chosen 1:3 as optimal parameter of aquaorganic ratio. At the extraction process, we chosen 1:3 of aqua-organic ratio, $3 \mathrm{~N}$ of chloride ion and $0.1 \mathrm{~N}$ of $\mathrm{A} 336$ with 1 minute mixing. With the condition above, we separated $99 \%$ of iron in this process.

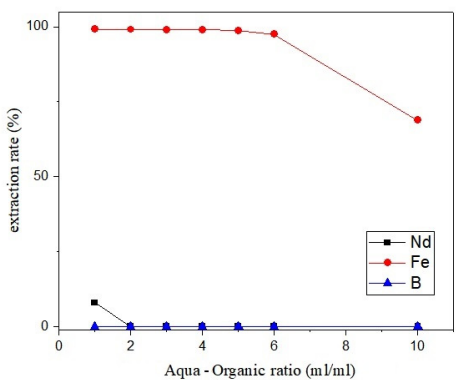

(0.1M A336, 3MHCl, 1 minute)

Fig. 7. The efficiency of aqua-organic ratio on extraction

\subsection{Chemical precipitation and calcination}

The result of precipitating neodymium by using oxalic acid is illustrated in Fig. 8. Co-precipitation effect occurred on boron, however, the content of boron in AMSS was less than $1 \%$. The co-precipitation only had a few effect to the neodymium purity. The neodymium 
oxalate was calcined by furnace at $1173 \mathrm{~K}$ with 30 minutes. The purity of neodymium oxide product was over $99 \%$.

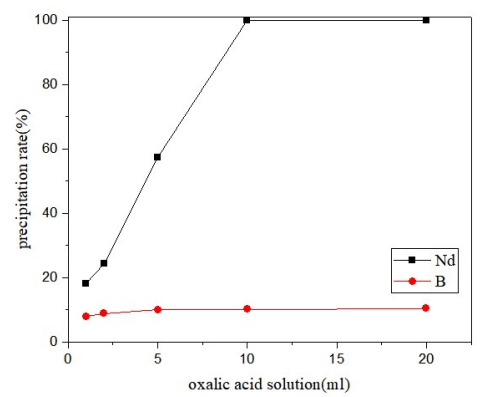

Fig. 7. Different volume of oxalic acid on neodymium precipitation

\section{Conclusion}

The suggested recovery process of AMSS is presented in Fig. 8. After roasting at $600^{\circ} \mathrm{C}$ with 6 hours, selective leaching would separate $89 \%$ of iron. The concentration of chloride ion would adjust by $\mathrm{HCl}$ to prepare the aqueous phase of solvent extraction. The rest of iron was separated by solvent extraction with Aliquat 336. The mass of oxalic acid requested added was calculated by the experiment above. Each litre of solution had to mix 18 grams of oxalic acid to precipitate $99 \%$ of neodymium. The neodymium oxalate was calcined at $900^{\circ} \mathrm{C}$ in 30 minutes to obtain neodymium oxide. The purity of final product was over $99 \%$ and recovery percent of neodymium was $99 \%$.

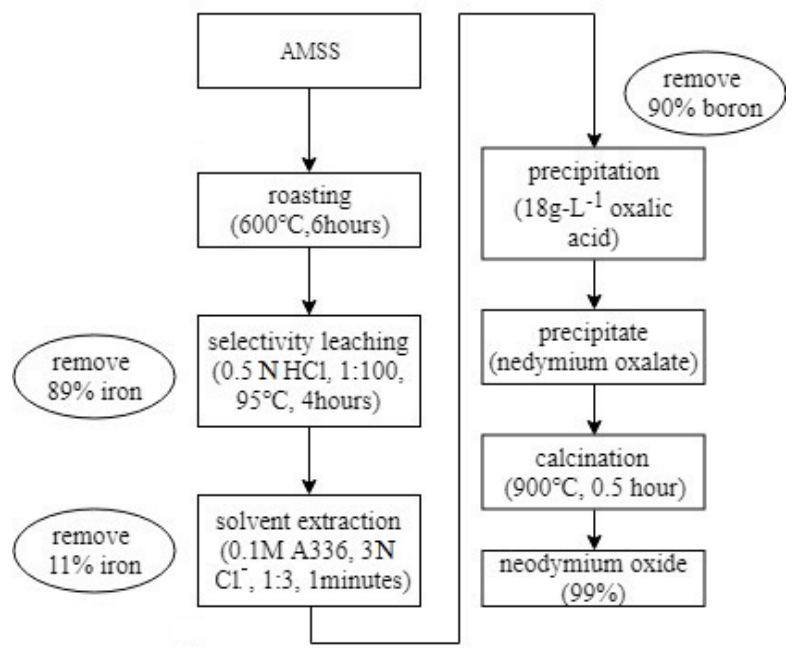

Fig. 8. Suggested recovery process of AMSS

\section{References}

1. Kim, J. W.; Kim, Y.Do.. J. Korean Powder Metall. 20, 169-173, (2013)

2. Miura, K.; Itoh, M.; Machida, K.. I. J. Alloys Compd. 466, 228-232 (2008)

3. Lixandru A.; Venkatesan P.; Jönsson C.; Poenaru I.; Hall B.; Yang Y.; Walton A.; Güth K.; Gauß R.; Gutfleisch O.. Waste Manag. 68, 482-489 (2018)
4. Popov V.; Koptyugb A.; Radulove I.; Maccaric F., Muller G.. Procedia Manuf. 21, 100-108 (2018)

5. Xu T.; PENG H.. J. Rare Earths, 27, 1096-1102 (2009)

6. Zhou B.; Li Z.; Chen C.. Minerals, 7, 203 (2017)

7. Li C.; Yue M.; Liu W.; Zuo T.; Yi X.; Chen J.; Zhou Z.; Wu Y. J.. Mater. Cycles Waste Manag. 17, 547552 (2015)

8. Li C.; Liu W.Q.; Yue M.; Liu Y.Q.; Zhang D.T.; Zuo T.Y.. IEEE Trans. Magn. 50, 3-5 (2014)

9. Zhang X.; Liu F.Liu Y.; Ma Q.; Li Y.; Zhao Q.; Gaofeng Wang G,; Li Z.. J. Magn. 20, 97-102 (2015)

10. Takeda O.; Okabe T.H.; Umetsu Y.. J. Alloys Compd. 408-412, 387-390 (2006)

11. Yoon H.S.; Kim C.J.; Chung K.W.; Kim S.D.; Kumar J.R.. J. Braz. Chem. Soc. 26, 1143-1151 (2015)

12. Walawalkar M.; Nichol C.K.; Azimi G. Hydrometallurgy. 166, 195-204 (2016)

13. Lee C.H.; Chen Y.J.; Liao C.H.; Popuri S.R.; Tsai S.L.; Hung C.E.. Mater. Trans. A Phys. Metall. Mater. Sci. 44, 5825-5833 (2013)

14. Rabatho J.P.; Tongamp W.; Takasaki Y.; Haga K.; Shibayama A.. J. Mater. Cycles Waste Manag. 15, 171-178 (2013)

15. Rout A.; Binnemans K. Ind. Eng. Chem. Res. 53, 6500-6508 (2014)

16. Mishra R.K.; Rout P.C.; Sarangi K.; Nathsarma K.C.. Hydrometallurgy. 108, 93-99 (2011)

17. Lee M.S.; Lee J.Y.; Kim J.S.; Lee G.S.. Sep. Purif. Technol. 46, 72-78 (2005)

18. Mowafy E.A.; Mohamed D.. J. Rare Earths. 33, 432438 (2015)

19. Kim J.S.; Kim H.S.; Kim M.J.; Lee J.; Kumar J.R.. TMS. 2015, 117-126 (2017)

20. Cui L., Zhao Z., Guo Y., Cheng F.. Sep. Purif. Technol. 199, 2017, 304-310 (2018)

21. VanderHoogerstraete, T. et al., RSC Adv. Royal Society of Chemistry. 4, 64099-64111 (2014) 